\title{
Problems with the variants or quasi-species of the Hepatitis B virus (HBV) in treatment
}

Angel San Miguel Rodríguez ${ }^{1}$, Angel San Miguel Hernández 2*, Julia San Miguel Rodríguez ${ }^{1}$ and Maria San Miguel Rodríguez ${ }^{1}$

${ }^{1}$ Research Unit Service. Río Hortega University Hospital. Valladolid. Spain.
${ }^{2}$ Clinical Analysis Service. Río Hortega University Hospital. International University of La Rioja (UNIR). Spain

Magna Scientia Advanced Biology and Pharmacy, 2021, 03(01), 013-018

Publication history: Received on 07 June 2021; revised on 09 July 2021; accepted on 11 July 2021

Article DOI: https://doi.org/10.30574/msabp.2021.3.1.0029

\begin{abstract}
The HBV genome has a very high mutation rate, which is why it is considered a highly variable virus, being able to produce different variants or quasi-species in the same host, differentiated by small mutations that favor the oncogenic potential of the virus, in addition to attenuating the immunogenicity and antigenicity.

There are a large number of epidemiological findings and studies that suggest a relationship between genotypes and pre-core / core variants of the hepatitis B virus with the clinical course of infection and the response to different antiviral treatments.
\end{abstract}

Keywords: Hepatitis B; HBV; Virus; Mutations; Variants; Quasi-species

\section{Introduction}

Hepatitis B is a life-threatening liver infection caused by the hepatitis B virus (HBV). It is a major health problem worldwide as it can cause chronic liver disease and carries a high risk of death from cirrhosis and liver cancer. It is estimated that there are 240 million people suffering from chronic hepatitis B virus infection, with more than 780,000 people dying each year as a result of this infection (WHO, 2015).

Despite the fact that the existence of vaccines and antiviral treatments has caused a notable reduction in cases of acute liver failure associated with HBV infection, its chronicity is still a major health problem worldwide [1].

HBV is a non-cytotoxic hepatotrope DNA virus belonging to the Hepadnavirus family, genus Orthohepadnavirus. The structure of HBV is formed by a lipoprotein coating that surrounds an icosahedral nucleocapsid, inside which are mainly the viral polymerase and the circular DNA formed by a complete and an incomplete DNA strand, which are circularized thanks to the complementarity between the 5 'ends of both strands [1]. Figure 1 shows the structure of the hepatitis B virus and figure 2 the genome of the virus.

When this virus is presented to the human immune system, it is capable of producing a humoral response against different antigens. The external face of the lipid bilayer of the virus presents an antigen known as surface antigen (HBsAg), against which antibodies are generated in the host. The current definition of chronic hepatitis B according to WHO is based on the demonstration of the presence of this antigen in the serum of a patient over a period of 6 months. HBsAg, also known as the Australia antigen, is made up of 3 proteins: $\mathrm{S}, \mathrm{M}$ and $\mathrm{L}$, in order from shortest to longest amino acid, encoded by the $\mathrm{S}$ gene. In its three-dimensional structure, this antigen reveals at least 5 epitopes conformational

\footnotetext{
${ }^{*}$ Corresponding author: Angel San Miguel Hernández

Río Hortega University Hospital. International University of La Rioja (UNIR). Spain
}

Copyright @ 2021 Author(s) retain the copyright of this article. This article is published under the terms of the Creative Commons Attribution Liscense 4.0. 
(HBs1-HBs5), forming the union of at least 3 of them the antigenic determinant "a" comprised between amino acids 121 to 149 of the $\mathrm{S}$ region, within the $\mathrm{S}$ gene [2].

On the other hand, inside the nucleocapsid is the Core antigen (HBcAg), also with immunogenic capacity. It is a small protein that forms dimers that assemble and form a Core icosahedral particle [3]. Its arginine-rich C-terminal end, located on the inside of the particles, is responsible for binding the pregenomic RNA for virus replication [4].

The amino acid chain of the core protein, together with 29 amino acids encoded in the pre-Core region, is processed by the Golgi apparatus releasing the e antigen (HBeAg) into the bloodstream, whose exact function is not known but it produces the Stimulation of B lymphocytes for the generation of antibodies, producing an immune response of the humoral type [5].

In addition to these antigens, there are other proteins and enzymes, such as protein $\mathrm{X}$ or polymerase, encoded in viral DNA. The polymerase of this virus has functions that in other viruses are carried out by independent enzymes. These activities are DNA polymerase, reverse transcriptase, and ribonuclease activity [6].

Due to the lack of proof-reading function and its reverse transcriptase activity, it presents a high mutation rate, also influencing in this aspect the overlapping of genes in the viral DNA. The HBV genome has a mutation rate of 1.4-3.2 $\times$ 105 substitutions/nucleotide/year, 100 times more than other DNA viruses [7]. This makes it a highly variable virus, being able to produce different variants or quasi-species in the same host, differentiated by small mutations that favor the oncogenic potential of the virus in addition to attenuating immunogenicity and antigenicity [8].

At least 10 different genotypes of HBV are currently known, named from A to J. For a variant to be recognized as a genotype of HBV it must have at least $8 \%$ of its nucleotide chain different from any other, being considered a subspecies if it presents from 4 to $8 \%$ different. There is evidence that the different genotypes and subspecies show a characteristic geographic distribution also related to the clinical progression and prognosis of the disease, in addition to influencing the response to treatment [9].

\section{Mutations in the viral DNA genes of the HBV virus}

The genome of the hepatitis B virus is made up of 4 genes that are found overlapping in the partial double-stranded DNA: gene $\mathrm{C}$, gene $\mathrm{S}$, gene $\mathrm{P}$, and gene $\mathrm{X}$.

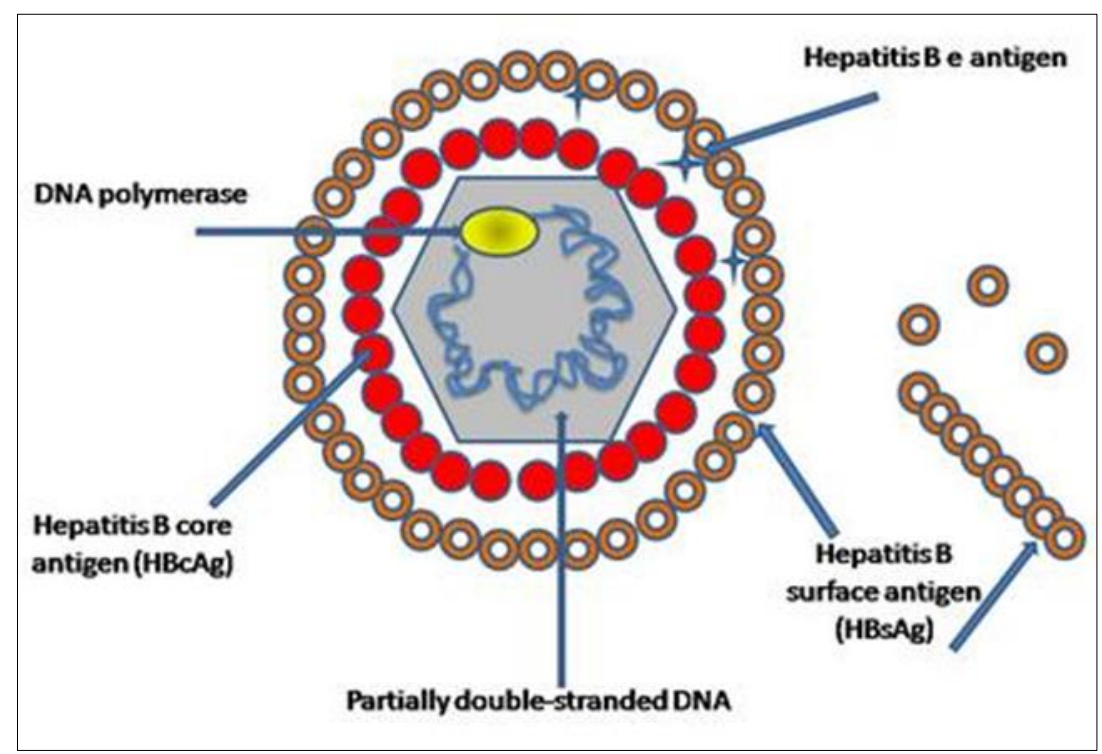

Figure 1 Structure of the hepatitis B virus. Taken from: Sabri MA. Hepatitis B: The Past, Present and the Future. Archives of Medicine 2018; 10:4. https://www.archivesofmedicine.com/medicine/hepatitis-b-the-past-present-andthe-future.pdf

The C gene, precore-core (preC / C), contains the information necessary to form the Core protein and the e antigen. Mutations that occur in the basal core promoter, ranging from amino acids 1742 to 1849 , can suppress the production 
of preC mRNA at the transcriptional level, thus contributing to the defective synthesis of HBeAg [10). Mutations in the Core and basal promoter regions of the Core are frequently found in patients who do not express the e antigen, are HBeAg mega-negative but do present active viral replication causing severe damage to liver function [11].

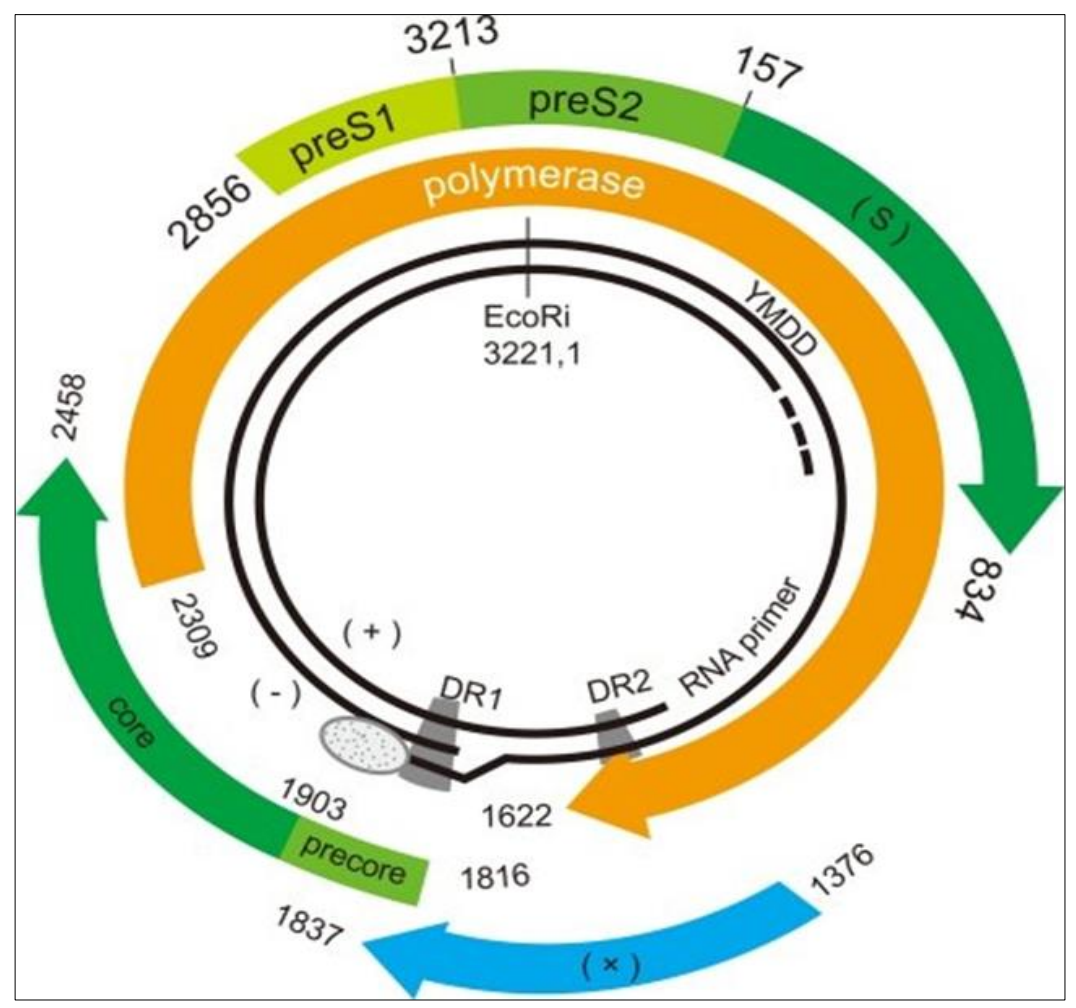

Figure 2 Genome of the hepatitis B virus. Taken from: Duaa W, et al. Hepatitis B Virus Molecular Epidemiology, HostVirus Interaction, Coinfection, and Laboratory Diagnosis in the MENA Region: An Update. Pathogens 2019, 8, 63; doi:10.3390/pathogens8020063

Mutations in the first amino acid of the pre-Core region, such as the A1814C / T, T1815C / A substitutions, are frequently found in genotype A patients and lead to failure in HBeAg production. Also the substitution of valine for phenylalanine at residue 17 of the pre-Core region (G1862T), can affect the expression of HBeAg interfering in the elimination of the peptidase signal [12]. But the most frequent mutation found in the pre-Core region affects the nucleotide located at position 1896, in which the UGG triplet passes to UAG (G1896A) generating a stop codon, which causes an entry impediment to the endoplasmic reticulum thus blocking the release of $\mathrm{HBeAg}$.

Most mutations in this region are generated during the seroconversion phase of chronic HBV infection. The Core protein or antigen is the main target of T lymphocytes, thus causing these mutations, persistent infections [13].

Mutations at the C-terminus of the preC / C region lead to alterations in the synthesis, transport, and secretion of $\mathrm{HBeAg}$. Thus, there is an accumulation of pro-protein HBeAg (p22) in the hepatocytes, observing a decrease in the active replication of the virus that causes a decrease in the viral load detected in the patient's serum [10]. A study published in 2012 found that a total of 5 pre-C/C mutations, G1896A in the preC region and 4 mutations in the $C$ region: E43K, P50A/ H/ Y, A131G / N / P and S181H / P, significantly related to the serological status of HBeAg in patients with chronic hepatitis B with the $\mathrm{C} 2$ sub genotype [13].

Another of the genes that make up the DNA of the hepatitis B virus is the S gene composed of 3 preS1 / preS2 / S regions, which when translated form the L, M, S proteins. These proteins give rise to the formation of the antigen. surface area, revealing, upon acquiring its three-dimensional structure, the determinant "a", the target of humoral immunity generated by HBV infection. Thus, the mutations that affect this epitope originate escape variants, both from natural immunity and from vaccination [2].

The vertical transmission of these variants was described for the first time in 1990, in an Italian study with children of carrier mothers who, having been vaccinated, developed the infection. One of the mutations found in this study is now 
one of the most frequently encountered vaccine escape variants: the change from a glycine to an arginine at amino acid 145 (G145R), belonging to the segment of the highly antigenic determinant of HBsAg [14]. Horizontal transmission has also been described in the presence of high HBsAc titers [15].

Sensitivity and accuracy in the serum detection of HBsAg is essential to detect hepatitis B virus infection, to reduce the window period in acute infection, and to detect escape variants and other mutated variants of HBV. In a study, the detection of mutated antigens according to some cases described in the scientific literature, recombinant and natural, of different immunoassays available in the diagnostic market was compared. According to the results they obtained, Abbot's immunoassays on different autoanalyzer's were the only ones capable of detecting all mutations in the $S$ gene present in the assay [16].

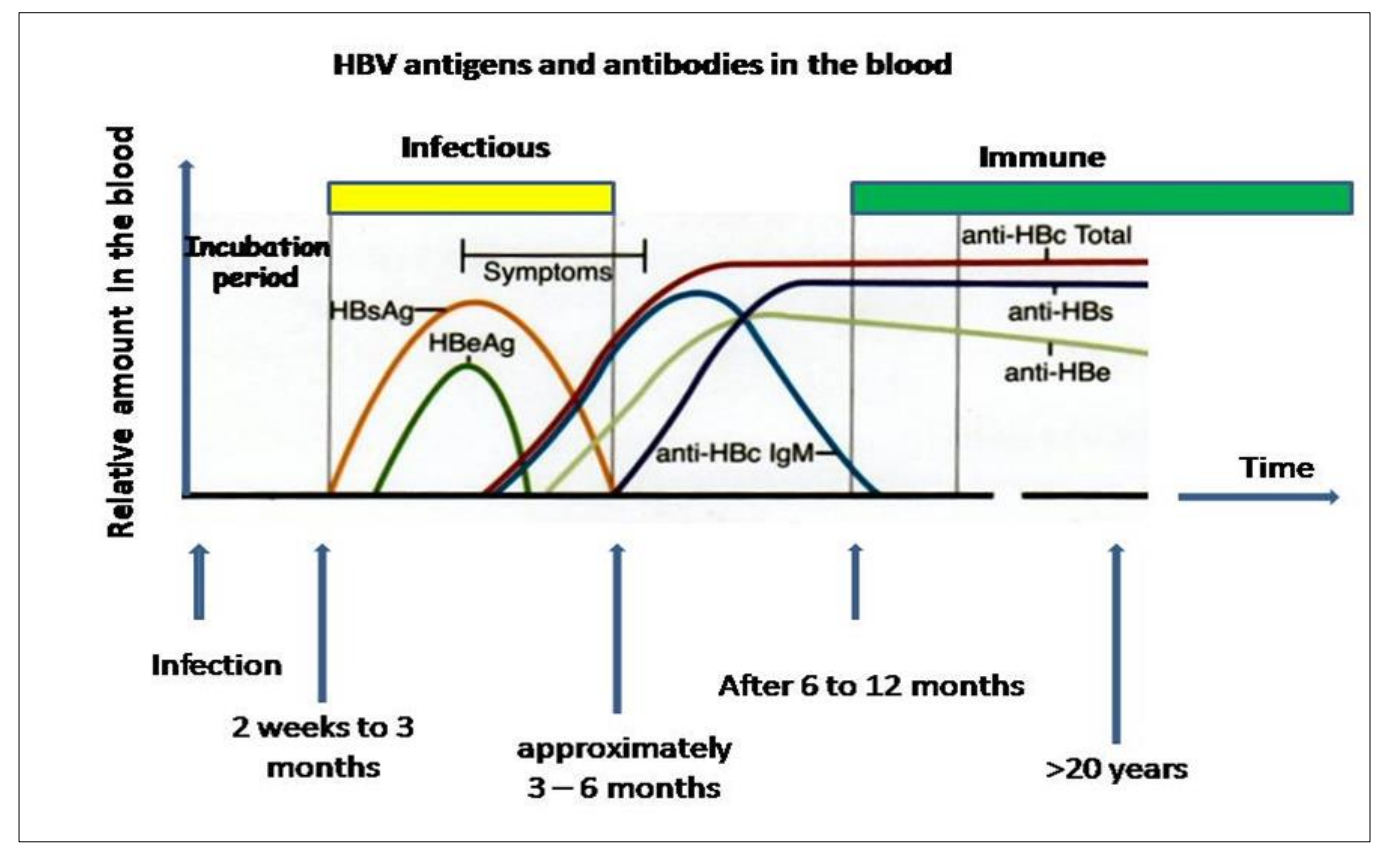

Figure 3 Serological markers of the Hepatitis B Virus. Taken from: Candotti D, Laperche S. Hepatitis B Virus Blood Screening: Need for Reappraisal of Blood Safety Measures? Frontiers in Medicine 2018: 5. Available in: https://www.frontiersin.org/articles/10.3389/fmed.2018.00029/full

The P gene codes for the formation of HBV polymerase, an enzyme used as a target in different antivirals used to treat this infection. Thus, mutations in this sequence that affect catalytic domains cause resistance to enzyme inhibitor treatments using nucleotide/nucleoside analogs. When it cannot be recognized by the polymerase, due to a mutation, the effect of the treatment is canceled and the virus replicates, thus increasing the viral load. Mutations in the YMDD region, highly conserved and essential for virus replication, can produce resistance and replication defects. The YVDD (rtM204V) and YIDD (rtM204I) mutations are related to resistance to L-nucleosides such as lamivudine, telbivudine and clevudine, and to entecavir [17].

Although the exact function of protein $\mathrm{X}$ is unknown, mutations in gene $\mathrm{X}$ have been documented in patients with hepatocellular carcinoma [18]. In these cases, we can find very low HBsAg values, so the diagnosis must be made by demonstrating the presence of genomic material, although it is an infrequent profile [7].

The recombinant HBV vaccine has been implemented mainly in highly endemic regions for infection against this virus. $92 \%$ of the countries in the world have implemented this vaccine with a global coverage of $69 \%$. Antibodies produced in response to the vaccine are directed against the HBsAg "a" determinant, but despite the availability of an effective vaccine, hepatitis B remains a global public health problem [19]. Mutant strains are scarcely or non-neutralized by antiHBs antibodies, acquiring a clear biological advantage over the wild strain that originated them: they have the possibility of replicating in the host from which they arise and in presumably immunocompetent vaccinated individuals [2].

There is consensus in considering that mutant strains in the S gene, regardless of their origin, can be transmitted vertically and horizontally and retain the ability to generate active infections, susceptible to chronification, in 
supposedly immune individuals. This can lead to the emergence and dissemination of these strains, generating an important public health problem [2].

In addition to the formation of escape variants due to mutations in the $\mathrm{S}$ gene by preventive treatment with passive immunization, there are variants that can confer resistance to a drug, to a family of drugs, even cross-resistance among several antivirals. These types of variants are more related to mutations in the polymerase gene (P gene). When a patient with hepatitis B, in whom they host this type of variants, is subjected to antiviral therapy, a positive selective pressure is exerted on the mutant strains, favoring their replication thanks to the elimination of the wild strain. The incidence of the appearance varies according to the viral load prior to treatment, the speed of the suppression of viral replication by the drug, the time of exposure to it and previous exposure to other antivirals [20].

In 2011 a study was published on an Abbott improved sensitivity and mutant detection assay for surface antigen detection. Compared with two other immunoassays, the detection of 9 mutants for the determinant "a" was evaluated, noting that this new assay improved the rest, detecting the mutants with the T123A and D144A substitutions and the insertion at position 122, within the region which forms the determinant "a" [21].

Mutations that cause a change in the antigen, whether it is surface antigen or HBeAg, mean that it is not detected in the patient's serum by commercial methods and this, together with the fact that these changes are capable of eluding the immune response and therefore Consequently, they complicate the detection of the disease by serological methods. This aspect is especially relevant in the transmission of the virus in transfusions and transplants, since mutants may not be detected [21].

\section{Conclusion}

At least 10 different genotypes of HBV are known, ranging from A to J. For a variant to be recognized as a genotype of $\mathrm{HBV}$ it must have at least $8 \%$ of its nucleotide chain different from any other, being considered a subspecies if it presents different from $4-8 \%$.

There is much evidence that the different genotypes and subspecies show a characteristic geographic distribution, also related to the clinical progression and prognosis of the disease, in addition to influencing the response to treatment.

The mutations that occur along the 4 genes that make up the genome of the hepatitis B virus and that are found overlapping in the partial double-stranded DNA have been reviewed: gene $\mathrm{C}$, gene $\mathrm{S}$, gene $\mathrm{P}$ and gene $\mathrm{X}$.

Therefore, the study of the different quasi-species of HBV are important for the optimization of therapeutic treatments.

\section{Compliance with ethical standards}

\section{Acknowledgments}

To all the professionals of the Hospital.

\section{Disclosure of conflict of interest}

The authors declare no conflict of interest.

\section{References}

[1] Garcia Alonso F, Martín Mateos R, Moreira Vicente V. Pharmacological treatment of acute hepatitis B. Med Clin. 2012; 138: 633-7.

[2] Navarro D, Esparcia O, Granda S. Mutantes del virus de la Hepatitis B en el gen S. SEIMC. 2006.

[3] Günther S, Fischer T, Pult T, Sterneck M. Natural accurring variants of hepatitis B virus. Adv Virus Res. 1999; 52: 25-137.

[4] Zlotnick A, Cheng N, Stahl SJ, Conway JF, Steven AC, Wingfield PT. Localization of the C terminus of the assembly domain of hepatitis B virus capsid protein: implications for morphogenesis and organization of encapsidated RNA. Proc Natl Acad Sci U S A. 1997; 94(18): 9556-61.

[5] Ou J. Molecular biology of hepatitis B virus e antigen. J Gastroenterol Hepatol. 1997; 12(9-10): S178-87. 
[6] Nassal M. Hepatitis virus B replication: novel roles for virus-host interactions. Intervirology. 1999; 42: 100-16.

[7] García Bermejo I. Anomalías y patrones serológicos infrecuentes de los marcadores diagnósticos del virus de la hepatitis B. Enferm Infecc Microbiol Clin [Internet]. 2007; 25: 21-8.

[8] Aragri M, Alteri C, Battisti A, Di Carlo D, Minichini C, Sagnelli C, et al. Multiple Hepatitis B Virus (HBV) Quasispecies and Immune-Escape Mutations Are Present in HBV Surface Antigen and Reverse Transcriptase of Patients With Acute Hepatitis B. J Infect Dis [Internet]. 2016.

[9] Sunbul M. Hepatitis B virus genotypes: Global distribution and clinical importance. World J Gastroenterol. 2014; 20(18): 5427-34.

[10] Kim H, Lee S-A, Do SY, Kim B-J. Precore/core region mutations of hepatitis B virus related to clinical severity. World J Gastroenterol [Internet]. 2016; 22(17): 4287.

[11] Wang X-L, Ren J-P, Wang X-Q, Wang X-H, Yang S-F, Xiong Y. Mutations in pre-core and basic core promoter regions of hepatitis B virus in chronic hepatitis B patients. World J Gastroenterol [Internet]. 2016; 22(11): 3268.

[12] Guarnieri M, Kim K-H, Bang G, Li J, Zhou Y, Tang X, et al. Point mutations upstream of hepatitis B virus core gene affect DNA replication at the step of core protein expression. J Virol. 2006; 80(2): 587-95.

[13] Kim H, Lee SA, Kim DW, Lee SH, Kim BJ. Naturally Occurring Mutations in Large Surface Genes Related to Occult Infection of Hepatitis B Virus Genotype C. PLoS One. 2013; 8(1).

[14] Carman W, Zanetti A, Karayiannis P, Waters J, Manzillo G, Tanzi E, et al. Vaccine-induced escape mutant of hepatitis B virus. Lancet. 1990; 11(336(8711)): 325-9.

[15] Chakravarty R, Neogi M, Roychouwddhury S, Panda C. Presence of hepatitis B surface antigen mutant G145R DNA in the peripheral blood leukocytes of the family members of an asymptomatic carrier and evidence of its horizontal transmission. virus Res. 2002; 90(1-2): 133-41.

[16] Moerman B, Moons V, Sommer H, Schmitt Y, Sletter M. Evaluation of sensitivity for wild type and mutant forms of hepatitis B surface antigen by four commercial HBsAg assays. Clin Lab. 2004; 50(3-4): 159-62.

[17] Locarnini S. Primary resistance, multidrug resistance, and cross-resistance pathways in HBV as a consequence of treatment failure. Hepatol Int. 2008; 2(2): 147-51.

[18] Sung W-K, Zheng H, Li S, Chen R, Liu X, Li Y, et al. Genome-wide survey of recurrent HBV integration in hepatocellular carcinoma. Nat Genet [Internet]. Nature Publishing Group, a division of Macmillan Publishers Limited. All Rights Reserved. 2012 Jul; 44(7): 765-9.

[19] Jaramillo CM, Navas M-C. [Escape mutants of hepatitis B virus]. Rev Chilena Infectol [Internet]. 2015; 32(2): 1907.

[20] Fung SK, Chae HB, Fontana RJ, Conjeevaram H, Marrero J, Oberhelman K, et al. Virologic response and resistance to adefovir in patients with chronic hepatitis B. J Hepatol. 2006; 44(2): 283-90.

[21] Lou SC, Pearce SK, Lukaszewska TX, Taylor RE, Williams GT, Leary TP. An improved Abbott ARCHITECT assay for the detection of hepatitis B virus surface antigen (HBsAg). J Clin Virol [Internet]. 2011; 51(1): 59-63. 